\title{
The Drosophila FGF-R homolog is expressed in the embryonic tracheal system and appears to be required for directed tracheal cell extension
}

\author{
Lillian Glazer and Ben-Zion Shilo ${ }^{1}$ \\ Department of Molecular Genetics and Virology, Weizmann Institute of Science, Rehovot 76100 Israel
}

The Drosophila homolog of the vertebrate fibroblast growth factor receptor (FGF-R) was isolated by low-stringency hybridization. In contrast to the diversity of this subclass of receptor tyrosine kinases in vertebrates, the Drosophila genome appears to encode only a single homolog. Nucleotide sequence analysis demonstrates that the Drosophila FGF-R homolog (DFGF-R) protein has a conserved sequence, size, and organization. The extracellular region encodes three immunoglobulin-like domains, and the cytoplasmic kinase domain exhibits a high degree of similarity to the vertebrate FGF-Rs with the typical split kinase and comparably sized juxtamembrane and carboxy-terminal regions. The DFGF-R was mapped to position 70C on the third chromosome, and two overlapping chromosomal deficiencies that remove the gene were identified. Developmental Northern blots show that the gene has a single transcript of $4.3 \mathrm{~kb}$ and is expressed at all stages of development. Localization of the transcript and protein in embryos has shown that the gene is predominantly expressed in a restricted set of tissues: the developing tracheal system and the delaminating midline glial and neural cells. In embryos homozygous for a deletion of several genes including the DFGF-R locus, the initial formation of the tracheal pits is not affected. However, the extension of tracheal cell processes leading to the formation of the elaborate tree structure is blocked. The DFGF-R protein may thus participate in receiving spatial cues that guide tracheal cell outgrowth.

[Key Words: Receptor tyrosine kinase; FGF; Drosophila embryonic development; trachea]

Received October 18, 1990; revised version accepted January 31, 1991.

The fibroblast growth factor (FGF) family of ligands consists of at least six different members identified by their heparin-binding activity (for review, see Burgess and Maciag 1989). These factors have diverse biological roles. In tissue culture they were shown to induce proliferation of most mesodermal and neuroectodermal cells (Gospodarowicz 1974). Abnormal expression of FGF was shown to lead to malignant transformation (Jaye et al. 1988; Neufeld et al. 1988; Rogelj et al. 1988). At the level of the whole organism, FGFs were shown to be crucial for the process of vascularization and wound healing (Folkman and Klagsbrun 1987) and may stimulate blood vessel growth into tumors, leading to tumor growth and invasiveness. Another important function of FGF is the induction of mesoderm formation in Xenopus embryos (Kimmelman and Kirschner 1987; Slack et al. 1987; Kimmelman et al. 1988).

The activities of acidic and basic FGFs were shown to be mediated by high-affinity binding to cell surface receptors (Neufeld and Gospodarowicz 1986). Several of these receptors have recently been cloned from human,

${ }^{1}$ This paper is dedicated to the memory of my father, Professor Moshe Shilo, a true scientist who exposed me to the wonders of biology. chicken, and mouse cDNA libraries and found to be members of the family of receptor tyrosine kinases (Kornbluth et al. 1988; Ruta et al. 1988; Lee et al. 1989; Dionne et al. 1990; Hattori et al. 1990; Pasquale 1990; Reid et al. 1990; Safran et al. 1990). The Xenopus (FGF-R) gene has also been isolated and shown to encode a highly conserved form of the protein (Musci et al. 1990). The FGF-R class appears to be most similar to the platelet-derived growth factor (PDGF) and colony stimulating factor (CSF-I) receptors and to the c-kit protein. Its extracellular portion has three immunoglobulin-like domains (for review, see Williams and Barclay 1988), and the cytoplasmic tyrosine kinase region is split. However, the FGF-R class also exhibits unique structural features, such as a relatively long juxtamembrane region, a short intervening domain splitting the kinase, and a short carboxyterminal tail. The diversity of FGF-Rs in vertebrates may reflect the parallel multiplicity of FGF-related ligands. The full range of ligands recognized by each of the receptors is not known yet. However, it appears that each of the FGF-R types can bind several FGF-related ligands (Dionne 1990).

On the basis of the wide spectrum of tyrosine kinases representing the receptor and nonreceptor class that 
were shown to be conserved in the genome of Drosophila melanogaster (for review, see Shilo 1987; Hoffmann 1990), we decided to search for an FGF-R homolog as well. The structure of over 10 Drosophila tyrosine kinases reveals that the major gene duplications in this large and diverse family have occurred prior to the arthropod-chordate split. Each Drosophila homolog is clearly most similar in sequence and overall organization to its vertebrate counterpart. In vertebrates, additional duplications have occurred, generating small subfamilies. In contrast, each of the members in Drosophila appears to be represented by a single gene, stemming perhaps from the lower complexity of this organism, requiring a lesser degree of microdiversity. This singularity makes subsequent genetic and biological analysis more straightforward.

The identification of tyrosine kinases in Drosophila opened the way to the elucidation of their biological roles. Isolation of mutations in the genes encoding several homologs provides the first insights into their function (Hafen 1987; Gertler et al. 1989; Price et al. 1989; Schejter and Shilo 1989; Sprenger et al. 1989; for review, see Hoffmann 1990; Pawson and Bernstein 1990). These tyrosine kinases appear to control a diverse set of processes involving communication between cells, such as determination of photoreceptor number and identity in the compound eye, determination of dorsoventral and terminal polarity of the embryo, and formation of the central nervous system. Some tyrosine kinases are expressed at a wide range of developmental phases and were shown to have pleiotropic roles [like the epidermal growth factor (EGF) receptor and $a b l$ homologs]. Others, such as sevenless and torso, are expressed at a single stage and were shown to have an effect restricted to that stage.

In this paper we describe the isolation of the Drosophila FGF-R homolog (DFGF-R) and show that it has a high degree of sequence similarity to its vertebrate counterparts. Most notably, all of the unique structural features of the FGF-R class have been conserved, including the three immunoglobulin-like domains at the extracellular region. During embryogenesis, the expression of DFGF- $R$ is confined to a restricted set of tissues: the developing tracheal tree and the delaminating midline glial and neural cells. Analysis of tracheal development in embryos homozygous for a deficiency removing several genes including the DFGF-R locus shows that the process of directed migration responsible for the formation of the elaborate structure of the tracheal tree is blocked.

\section{Results \\ Isolation and sequence of the DFGF-R}

To screen for Drosophila homologs of the vertebrate FGF-R, we used as a probe a $1.7-\mathrm{kb}$ cDNA fragment of the mouse FGF-R (Safran et al. 1990; kindly provided by Y. Yarden and D. Givol), encoding a region spanning both the extracellular and kinase domains. From our pre- vious experience, the kinase domain always shows the highest degree of structural conservation and thus provides the best probe for this purpose. However, complications of cross-hybridization with other Drosophila tyrosine kinases have to be taken into account. A genomic library was screened under two sets of hybridization conditions. In one case, when the hybridization solution included formamide, nine clones were isolated; all were shown to contain the same genomic sequences and encode the receptor described below. When a parallel pool of phages was screened with the same probe in the absence of formamide, three types of clones were isolated (two independent clones of each type). One class is identical to the clones picked in the first screen. Sequence analysis of the homologous region within the other two types and in situ hybridization to polytene chromosomes revealed that they are identical to two previously described Drosophila receptor tyrosine kinases. One encodes the Drosophila ret homolog mapping to position 39B (E. Hafen, pers. comm.); the other encodes the sevenless gene at position $10 \mathrm{~A}$. In vertebrates, the ret receptor is distinct from the FGF-R class but represents the member most similar to it (Pasquale 1990). From our inability to isolate more than one clone that corresponds directly to the FGF-R class, we conclude that there is a single FGF-R homolog in the Drosophila genome. This observation is in accordance with the previous findings that the EGF and insulin receptor classes are each represented by a single member in Drosophila.

Southern blot analysis was used to identify the genomic fragment within the Drosophila FGF-R clone, containing the homology to the mouse FGF-R probe. This genomic fragment was then used as a probe to isolate cDNA clones from an embryonic 3- to 12-hr library. The sequence of the genomic and CDNA clones was determined and is shown in Figure 1. The genomic and cDNA clones are colinear, except for an 85-bp intron located within the kinase domain. Even the longest cDNA clone did not include the signal for initiation of translation, but the sequence of the genomic clone allowed us to obtain further $5^{\prime}$ sequences that conformed to the expected structure of the extracellular domain, until a probable intron sequence was reached. We are thus missing the sequence for the extreme $5^{\prime}$ end, which contains the expected signal sequence.

Alignment of the translated sequence to that of the mouse FGF-R shows a high degree of similarity in structure and overall organization (Figs. 2 and 3). At the extracellular region three typical immunoglobulin-like domains are detected. They are unambiguously identified on the basis of the presence of two cysteines within each domain, separated by 66,45 , and 59 amino acids, respectively (Williams and Barclay 1988). Many other conserved residues, especially around the cysteines, are identified and agree with the consensus: VX(I or L)XC(8-12)-W-(20-50)-DXGXYXC. The three immunoglobulin-like domains are encoded by a single exon, thus excluding the possibility of translation of receptors with structural variability at the extracellular domain, like those identified in vertebrates (Reid et al. 1990). An un- 


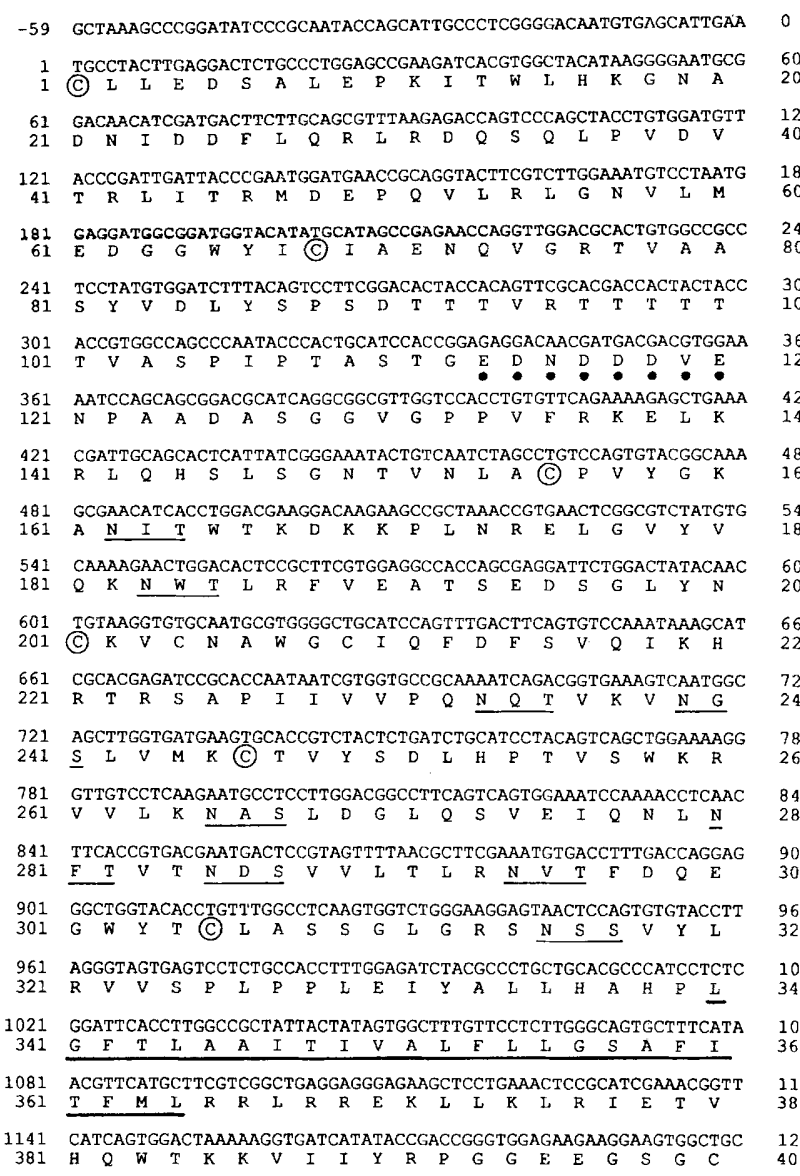

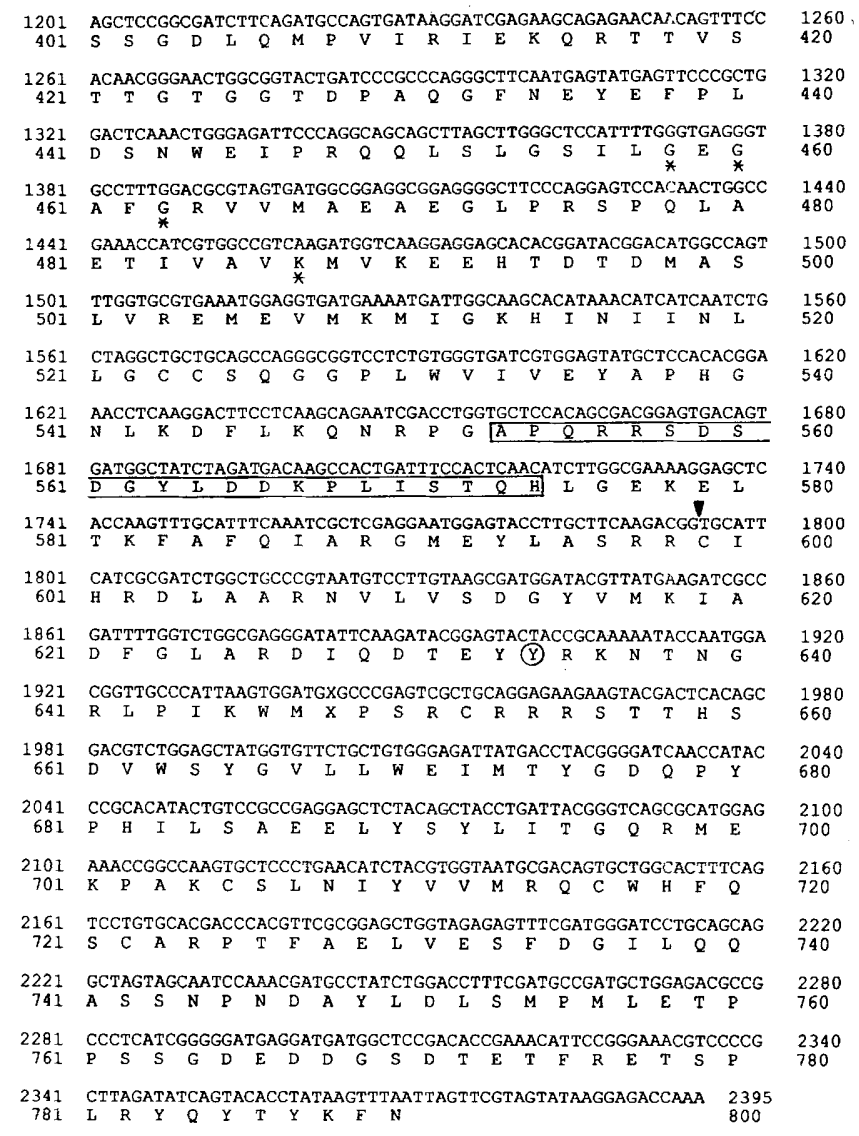

Figure 1. Nucleotide and amino acid sequence of DFGF-R. The cysteine pair in each immunoglobulin-like domain is circled. Putative glycosylation sites are underlined. The acidic domain is dotted. The transmembrane domain is underlined with a heavy line. The ATP-binding site is marked with asterisks $\left({ }^{*}\right)$, and the kinase insertion sequence is boxed. The position of the 85-bp intron is indicated by an arrowhead. The conserved tyrosine 634 residue, corresponding to the $\mathrm{pp}^{\mathrm{s}} 0^{\text {src }}\left(\mathrm{tyr}^{416}\right)$ major phosphorylation site, is circled. (Because cDNA clones encoding the signal peptide of DFGF-R have not yet been isolated, the numbering of the sequence begins at the first cysteine of the first immunoglobulin-like domain.) DFGF-R sequence data have been submitted to EMBL/GenBank under accession number X57746.

usual structural feature identified in the vertebrate receptors is the presence of several consecutive acidic residues between the first and second immunoglobulin domains. The Drosophila sequence has a similar stretch of EDNDDDVE at the same position.

Following the transmembrane domain of 25 residues, a relatively long juxtamembrane sequence of 90 residues, typical of the FGF-R class, is observed. The cytoplasmic domain of the DFGF-R shows the highest degree of sequence identity in the kinase region $(60 \%)$. The ATPbinding consensus sequence of GXGXXG is conserved. The kinase is split by 22 residues at a similar position to the vertebrate counterparts. The sequence conservation at this small kinase insert is low, but its size is similar to the 14-residue vertebrate FGF-R insert. Another special feature of the FGF-R class is a short carboxy-terminal tail of $\sim 70$ amino acids following the kinase region. Again, the DFGF-R has a carboxy-terminal tail of a similar size with a low degree of sequence conservation. The tail includes four tyrosine residues that could serve as autophosphorylation sites.

\section{Cytogenetic localization}

The nucleotide sequence of the DFGF-R has confirmed that it is a new member of the tyrosine kinase family in Drosophila. To map the gene, a biotinylated probe was prepared from the genomic phage clone and hybridized to polytene chromosomes. Hybridization was detected on the left arm of the third chromosome at position 70C, in close proximity to the $70 \mathrm{C} / \mathrm{D}$ boundary (Fig. 4A). To confirm the localization and obtain chromosomes bearing a deficiency for the DFGF-R gene that could subsequently be used for genetic analysis, two deficiency stocks were examined. They contain a deficiency of the 70B-70D and 70C-70E region, respectively (the overlap between them being 70C-D). The deficiency stocks were grown over a third chromosome balancer, and equal amounts of DNA were digested and probed with the DFGF-R clone. Figure 4B shows that the two stocks have a significantly reduced signal of hybridization compared to DNA extracted from wild-type flies. The presence of equal amounts of DNA on the blot was confirmed by the 


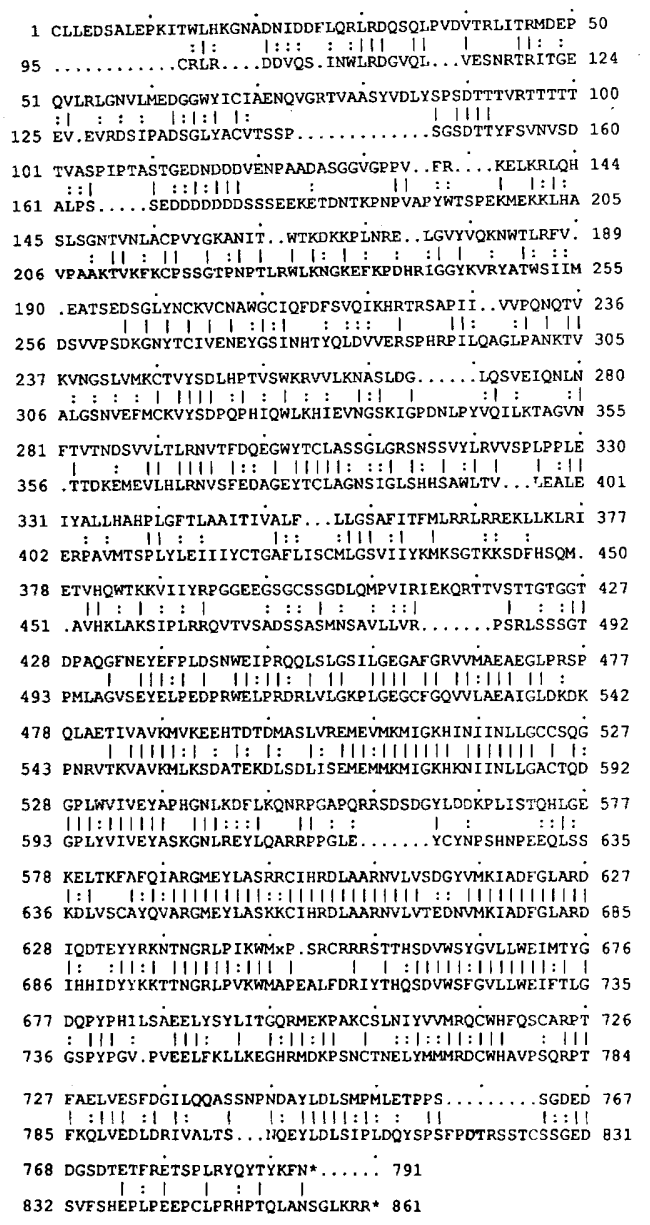

Figure 2. Alignment of the DFGF-R and the murine flg amino acid sequences. Top line indicates the sequence of DFGF-R. Identities are shown by vertical lines. Two dots denote the presence of conservative amino acid changes.

similar hybridization signals to a probe of the Drosophila EGF receptor (DER) gene, residing on the second chromosome.

Some tyrosine kinase genes were shown to be allelic to previously identified mutations with informative embryonic cuticle phenotypes. We wanted to check whether the DFGF-R locus is allelic to the shade mutation. This mutation was isolated in the screen for mutations on the third chromosome affecting the pattern of the larval cuticle (Jürgens et al. 1984) and represents the only mutation of this kind that maps to the region. The shade mutant was crossed to the two deficiencies; it was lethal over the 70C-E deficiency but viable over the second deficiency, thus ruling out its possible relationship to the DFGF-R locus.

\section{DFGF-R transcription}

To follow the pattern of transcription of the DFGF-R locus, developmental Northern blots were probed with the $2.3-\mathrm{kb}$ DFGF-R cDNA probe. A single poly $(\mathrm{A})^{+}$tran-

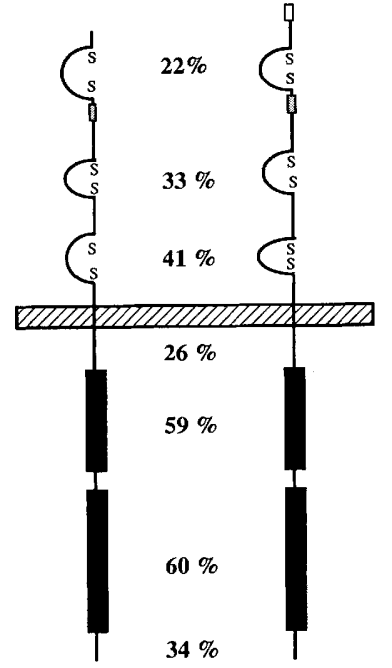

Figure 3. A scheme of the DFGF-R protein structure (left $)$ and its homology to the mouse FGF receptor (murine flg); (right). Percentages show amino acid identities for each region. The acidic domain is shown as a shaded box.

script of $4.3 \mathrm{~kb}$ was detected (Fig. 5). This transcript is similar in size to that of the vertebrate FGF-Rs. The transcript is detected at all stages of development, the level being highest in 0 - to 12 -hr embryos. The expression at multiple stages of development puts this gene in the category of the EGF and insulin receptor homologs, which were shown to be expressed throughout development (Lev et al. 1985; Petruzzelli et al. 1986) and to have a pleiotropic role. In contrast, torso and sevenless have

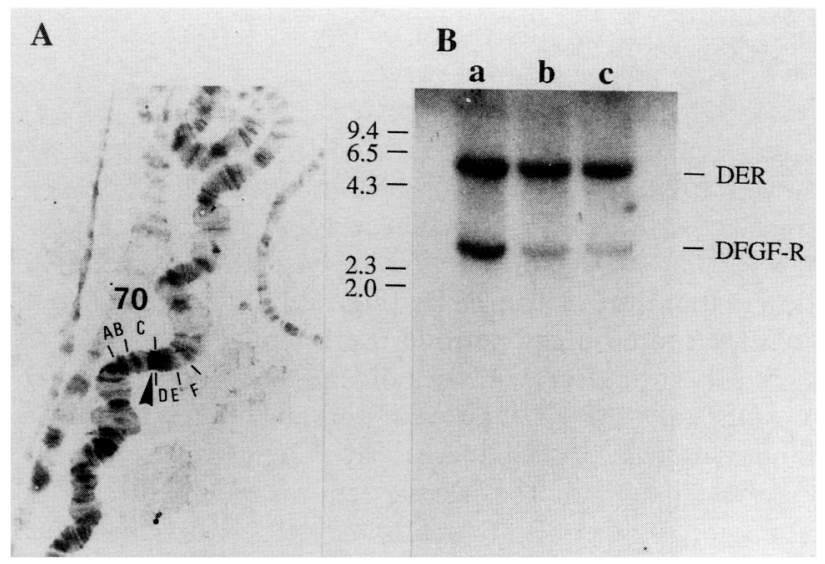

Figure 4. Chromosomal localization of the DFGF-R gene. $(A)$. The arrowhead shows the signal at $70 \mathrm{C}$ obtained after hybridization of the DFGF-R genomic phage clone and the horseradish peroxidase reaction. $(B)$ A Southern blot of genomic DNA digested with HindIII and probed with the DFGF-R 2.3-kb cDNA (bottom band) or the 3-kb DER cDNA probe (top band). (Lane a) DNA extracted from wild-type CS flies; (lane b) DNA from fz $\mathrm{GF}^{3 \mathrm{~b}} / \mathrm{TM} 6 \mathrm{~B}$ flies (Df. 70B-70D6); (lane $c$ ) DNA from $\mathrm{fz} \mathrm{GS}^{1 \mathrm{la}}$ / TM3 flies (Df. 70C6-15- to 70E4-6). Molecular weight markers are in $\mathrm{kb}$. 


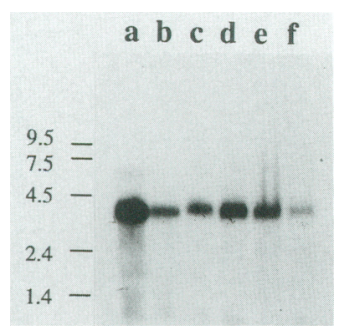

Figure 5. Developmental expression of the DFGF-R gene. Poly $(\mathrm{A})^{+}$RNA was extracted from different developmental stages. The blot was probed with a $2.3-\mathrm{kb}$ cDNA antisense RNA probe. (Lane $a$ ) 0- to 12-hr embryos; (lane b) 12- to 24-hr embryos; (lane $c$ ) first-instar larvae; (lane $d$ ) second- and third-instar larvae; (lane $e$ ) pupae; (lane f) adult flies. RNA molecular weight markers (from BRL) are in $\mathrm{kb}$.

functions that are restricted to a single stage and are thus correspondingly expressed (Hafen et al. 1987; Sprenger et al. 1989).

To localize the transcripts during embryogenesis, whole-mount RNA hybridization was carried out, using a dioxigenin antisense RNA probe prepared from the DFGF-R cDNA. Hybridization signals could be detected at the extended germ-band stage (Fig. 6a). They are identified as 10 lateral domains on either side of the embryo. The signals of hybridization mark the developing tracheal pits and appear to be restricted to the cells surrounding the pits.

\section{Localization of the DFGF-R protein}

To obtain a higher level of resolution than that of the RNA hybridization, antibodies recognizing the DFGF-R proteins were generated. A fragment containing either the entire extracellular region or the transmembrane and cytoplasmic domains was fused, in-frame, to the pATH vector. The induced fusion protein was used to immunize guinea pigs. Only the sera obtained against the transmembrane and cytoplasmic domains proved positive in the immunohistochemical analysis. It demonstrated that the localization of the protein is similar to the localization of the RNA (Fig. 6b). At stage 10, ten small periodic bulges, termed the tracheal placodes, appear on the lateral epidermis (Campos-Ortega and Hartenstein 1985). The protein is localized at that stage to the cells within the developing placodes (not shown).
At stage 11, following mitosis of the medial cells within each indentation, an invagination occurs, forming the deep narrow tracheal pits. The DFGF-R protein is localized to the epidermal cells lining the groove of the tracheal pits that are formed (Figs. $6 \mathrm{~b} ; 7 \mathrm{a}, \mathrm{b})$. All 10 pits on either side show a similar staining pattern. After invagination, the tracheal pits form small transversal tubes oriented perpendicularly to the extended germ band. At the end of stage 11 they also develop a crossbar oriented transversely. The presence of DFGF-R continues to be detected in the developing tubes (Fig. 7c). At germ-band shortening (stages 12-13), each crossbar comes into contact with its anterior and posterior neighbors, and the fusion between them generates a continuous structure with an opening at either end of the embryo. The DFGF$R$ is clearly detected on the cells forming this continuous tracheal tree (Fig. 7d). In all cases the immunohistochemical signal detected by antibodies against the DFGF-R protein appears to outline the cell membranes.

In addition to the localized expression of the DFGF-R in the developing tracheal system, two other sites of expression were identified at the extended germ-band stage. In the stomodeal opening, the cells opposite the clypeolabrum are stained. In addition, cells forming a narrow stripe (one to two cells wide) along the ventral midline of the embryo are expressing DFGF-R (Fig. $7 \mathrm{~b}$ ). The pattern of staining of these cells appears periodic, with a weaker signal in the region opposite the tracheal pits. These cells represent the midline glial and neural cells, delaminating from the meso-ectodermal cell layer.

\section{A deficiency in the DFGF-R locus leads to defects in tracheal development}

The restricted expression of the DFGF-R locus to the tracheal cells suggested that it may be important for the development of this system. Attempts are currently under way to isolate ethylmethane sulfonate (EMS)induced mutations in the locus and follow their phenotype. The availability of chromosomal deficiencies removing the locus, however, allows us to test the involvement of the protein in tracheal development even before point mutations in the DFGF-R gene are obtained. The overlap between the two deficiencies described above encompasses several genes, and the cuticle phenotype of the mutant embryos shows several defects, most notably the occasional fusion of segments (not shown).
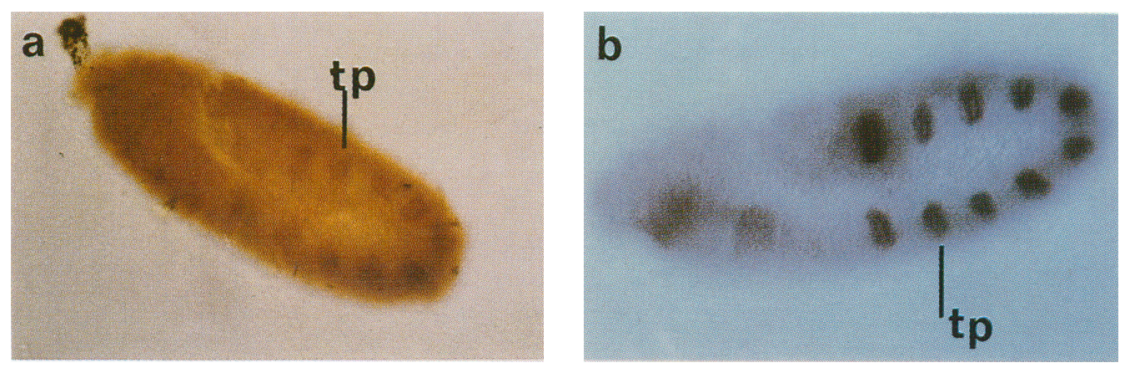

Figure 6. The DFGF-R transcript and protein are expressed in the embryonic tracheal pits. Whole-mount staining was carried out with dioxigenin-antisense RNA probes $(a)$ or with anti-DFGF-R antibodies directed against the cytoplasmic domain (b). In both cases, staining around the 10 tracheal pits (tp) can be observed in these embryos (stage 11). 
Figure 7. Developmental profile of DFGF-R protein localization. Staining is first observed at stage 10 , in 10 placodes that will give rise to the invaginating tracheal pits (not shown). At stage 11, the layer of cells surrounding the invaginating tracheal pits (tp) shows staining (a). A ventral view of an embryo at the same stage $(b)$ shows staining of the ventral midline cells (vm) and in the stomodeal opening (so). At stage 12 , the tracheal pits extend laterally and horizontally but are not connected yet (c). Following germ-band retraction, the DFGF-R protein is expressed in all the cells that form the tracheal tree $(d)$.
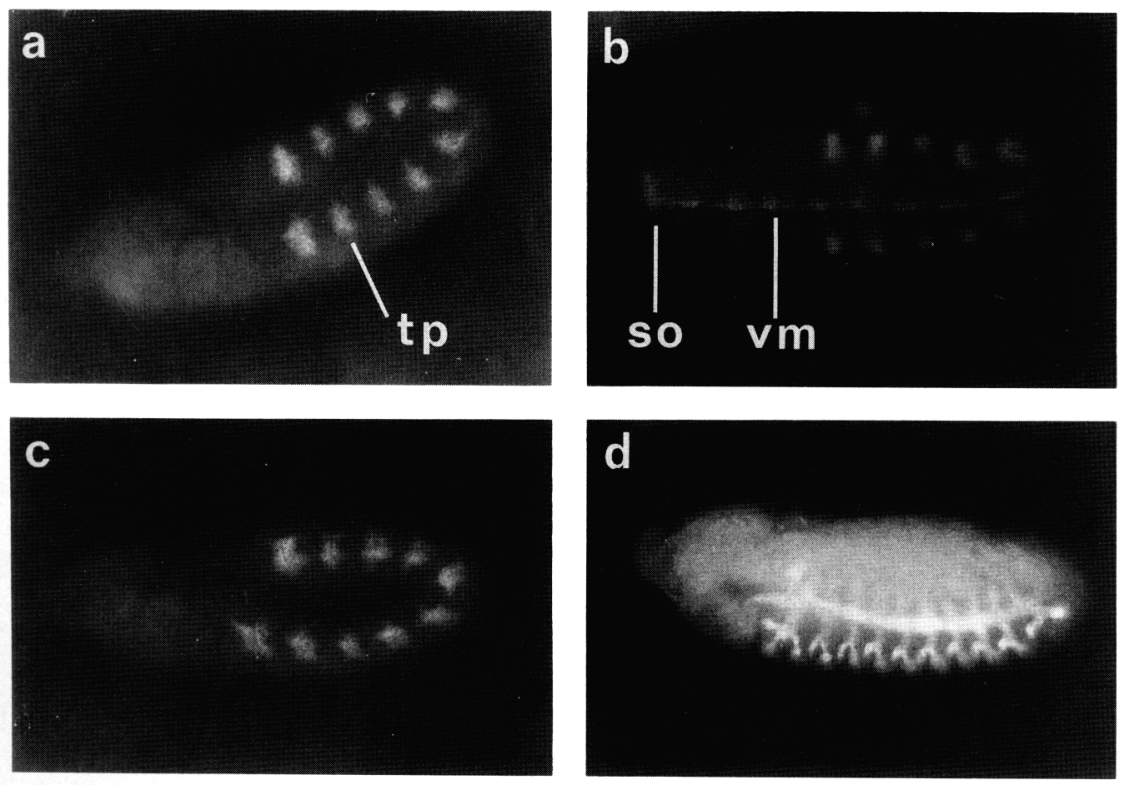

However, because DFGF-R is expressed in the tracheal system, any observed defects in this tissue are likely to be caused exclusively by the absence of the DFGF-R locus. The DFGF-R antibodies could no longer be used to follow the developing tracheal system in the deficiency background. Instead, anti-crumbs monoclonal antibodies (kindly provided by E. Knust) were used. These antibodies were shown previously to stain, among other tissues, the developing tracheal pits and subsequently the tracheal tree (Tepass et al. 1990).

Flies bearing the two deficiencies uncovering the DFGF-R locus were crossed, and the embryos were stained with anti-crumbs antibodies. This staining allows us to follow the tracheal system and compare its development in the wild-type and mutant embryos resulting from the cross. At the initial phase of tracheal development, no defects were observed. This phase lat stages 10-11) involves extensive cell divisions in the tracheal placodes that give rise to the tracheal pits.

At the second stage of tracheal development, however, defects were observed in the mutant embryos. In wildtype stage 12 embryos, as germ-band retraction commences, the tracheal pits begin to generate the elaborate structure of the tree, and the openings of the pits close (Fig. 8a). This process does not involve cell division but, rather, a dramatic change in tracheal cell shape (CamposOrtega and Hartenstein 1985). The existing tracheal cells extend narrow processes that connect to each other and form the outline of the tracheal tubes (V. Hartenstein, pers. comm.|. The formation of the intricate outlines of the tracheal tree takes place predominantly at stage 13 and onward, upon completion of germ-band retraction (Fig. 8b). From stage 12, defects in the tracheal system appear in the mutant embryos (Fig. 8c). These defects become more prominent at stage 13 and onward (Fig. $8 \mathrm{~d}$ ). The cells comprising the tracheal pits extend to a limited extent but fail to form the highly organized structure of the tree. In contrast to wild-type embryos in which the tracheal pattern is identical from segment to segment, in mutant embryos the tracheal invaginations take on a different and random pattern in each segment (Fig. 8c,d). The invaginations remain as circular cavities in some segments, whereas they partially elongate in others. In the mutant embryos the tracheal pits are sealed from the epidermal layer normally, and the aberrant structures develop as internal cavities.

On the likely assumption that the defects we observed in tracheal development result exclusively from the absence of the DFGF-R gene, what does the phenotype reveal about the normal role of the gene? Because the formation of the tracheal pits appears normal, we can unambiguously conclude that the DFGF-R is not required for the initial stages in which the tracheal pits are formed by cell divisions. The receptor appears to be required in the second phase of tracheal development, during the extension of the cells that form the elaborate structure of the tree. In mutant embryos, no directed cell migration appears to take place. The receptor is thus likely to be involved in recognition of cues that guide the extension of tracheal cells. These cues may be diffusible or anchored to cell surfaces or to the extracellular matrix.

\section{Discussion}

We have described the isolation of a Drosophila gene encoding a homolog of the FGF-R class of receptor tyrosine kinases. The putative DFGF-R protein is extremely similar in structure and overall organization to its vertebrate counterparts and appears to represent the only Drosophila homolog. DFGF-R contains three immunoglobulin domains at its extracellular region and is thus a 

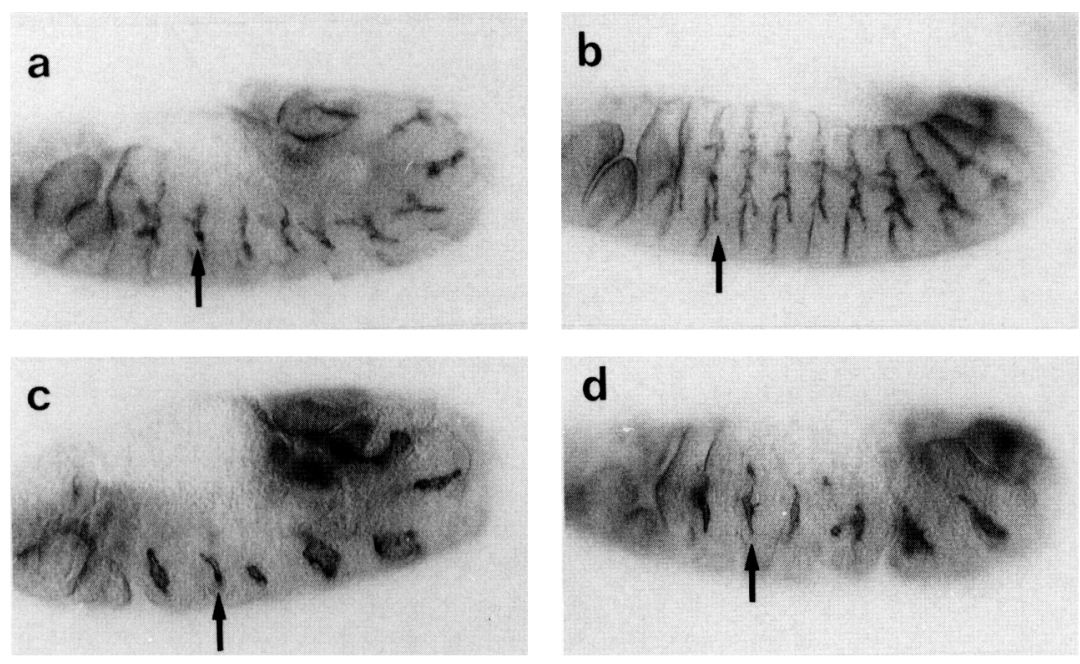

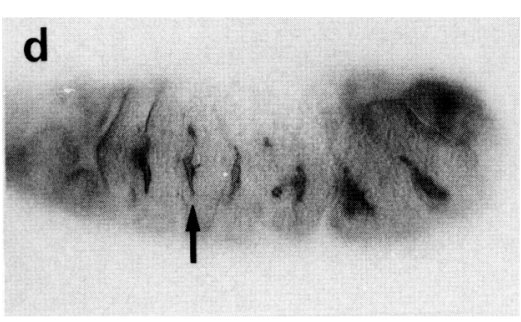

Figure 8. Aberrant migration of tracheal cells in embryos deficient for the DFGF-R locus. Flies bearing the two overlapping deficiencies of the $70 \mathrm{C}$ region were crossed, and their progeny stained with anti-crumbs antibodies, which mark the developing tracheal system. (a) In wild-type embryos at stage 12 , the tracheal tubes begin the process of elongation by cell migration but are not yet interconnected. (b) In wild-type embryos at stage 13, the tracheal processes become more elongated and delicate and are interconnected by the transversal tracheal stem. Note the highly reproducible pattern from one segment to the next. (c) In embryos homozygous for the overlapping $70 \mathrm{C}$ deficiencies at stage 12 , the tracheal pits can be visualized, but no significant cell migration leading to the extension of the tubes can be detected. Structural differences between the pits of each segment are apparent, indicating that a limited extent of misguided cell migration has taken place. (d) In mutant embryos at stage 12-13, the irregular pattern of the trachea is retained, and the extent of outgrowth of the trachea is significantly limited. The trachea do not develop further at later stages of embryonic development, and the transverse tracheal stems are never seen. Arrows mark the trachea. new member in the growing family of Drosophila proteins with similar extracellular domains. This is a diverse family including the fasciclin and neuroglian proteins (for review, see Grenningloh et al. 1991), phosphotyrosine phosphatases (Streuli et al. 1989), and amalgam (Seeger et al. 1988). Although the fasciclins mediate homophilic cell-cell recognition (Snow et al. 1989; Grenningloh et al. 1991), some of the other molecules (including DFGF-R) are likely to participate in heterophilic interactions with membrane-bound or diffusible molecules.

The DFGF-R gene was shown to be expressed at all stages of development. During embryogenesis, its expression is restricted to a narrow range of tissues: the developing tracheal system, and the delaminating midline glial and neural cells. Future studies with mutations in the DFGF-R locus should reveal its possible roles in the migration or differentiation of the midline cells. It would be interesting to determine whether the expression of DFGF-R at the larval and pupal stages also show a specific pattern giving clues to its later roles during development. It is important to note that DFGF-R is not expressed during the formation of the mesoderm and is not found in any mesodermal tissue. This is in contrast to the crucial role in mesoderm induction of the Xenopus FGF-related proteins (Kimmelman and Kirschner 1987; Slack et al. 1987; Kimmelman et al. 1988).

Analysis of tracheal development in mutant embryos strongly suggested that the DFGF-R protein may mediate signals for the processes of directed cell migration and recognition, which are likely to be crucial for the formation of the elaborate tracheal pattern. An interesting corollary to vertebrate systems emerges from the expression of DFGF-R in the tracheal system. In vertebrates, FGFs were shown to be potent angiogenic factors, capable of inducing growth and extension of the vascular system (Folkman and Klagsbrun 1987). Both basic and acidic FGF affect the vascular endothelial cells directly by promoting their mitosis and locomotion, the two key events in neovascularization. This direct effect suggests that the receptors for FGF are expressed on the endothelial cell surface. In Drosophila, DFGF-R may similarly mediate the extension of tracheal cell processes, which are crucial for the formation of the single-layered tracheal tubular structures.

The similarities between the possible function of the DFGF-R protein and the function of other molecules containing immunoglobulin-like domains in Drosophila are also apparent. The fasciclin proteins are expressed along defined surfaces of embryonic central nervous system axons and are likely to guide the migration of axons through homophilic interactions (for review, see Grenningloh et. al. 1991). In the case of the migration of the tracheal cells, it is more likely to assume that the process is controlled by heterophilic interaction between the DFGF-R protein and its ligand.

Future work should address the identity of the DFGF$\mathrm{R}$ ligands, which are likely to provide the cues guiding the formation of tracheal cell processes by activating the DFGF-R protein. Doctor et al. (1990) have shown that Drosophila tissue culture cells express, at low levels, a receptor capable of binding basic, but not acidic, FGF of vertebrate origin. Cross-linking experiments suggest that the size of this receptor is comparable to the size of the processed vertebrate FGF receptors. It is thus possible that the protein they identified by cross-linking is the DFGF-R protein. The ability of the receptor to recognize basic FGF suggests that the structure of its authentic ligand(s) may be similar. Furthermore, the propensity of FGF-like molecules to bind heparan-sulfate proteoglycans present on the cell surface or in the extracellular matrix makes them excellent candidates for the spatial 
cues that guide the extension of tracheal cells, which appears to be mediated by DFGF-R.

Another central question concerns the nature of substrate proteins that are phosphorylated following activation of this receptor tyrosine kinase and how their phosphorylation leads eventually to the establishment of tracheal patterns. An attractive possibility is that following activation of DFGF-R by its ligand, the contacts of the tracheal cell processes with the extracellular matrix or neighboring cells are stabilized by tyrosine phosphorylation of the cytoplasmic domains of adhesion molecules or extracellular matrix receptors.

\section{Materials and methods}

\section{Library screens and sequencing}

To isolate the DFGF-R gene, a $1.7-\mathrm{kb}$ SphI fragment of the mouse FGF-R clone was labeled by random priming and used to screen a genomic partial EcoRI library. The library was screened under two sets of hybridization conditions $162^{\circ} \mathrm{C}, 5 \times \mathrm{SSC}$, or $42^{\circ} \mathrm{C}, 35 \%$ formamide). To isolate cDNA clones, an embryonic 3- to 12-hr cDNA library in gt10 phage (Poole et al. 1985) was screened under conditions of high stringency with the $0.37-\mathrm{kb}$ PstI genomic fragment of the DFGF-R clone. The genomic and cDNA clones were sequenced using the Sequenase kit /U.S. Biochemical), and synthetic 17-mer oligonucleotides were synthesized as primers at $\sim 200$-bp intervals.

\section{In situ hybridization to polytene chromosomes}

The clone of the genomic DFGF-R phage was used as a probe for in situ hybridization, after verification that it did not contain repetitive sequences. It was biotin-labeled with Bio-16-dUTP. Enzymatic detection of the biotinylated probes was done using a strepavidin-horseradish peroxidase conjugate (ENZO Biochemicals), followed by staining with diaminobenzidine.

\section{Fly stocks}

The stocks $\mathrm{f} z \mathrm{GF}^{3 \mathrm{~b}} / \mathrm{TM} 6 \mathrm{~B}$ and $\mathrm{f} z \mathrm{GS}^{\mathrm{la}} / \mathrm{TM} 3$ contain a deficiency of the region $70 \mathrm{~B}-70 \mathrm{D} 6$ and $70 \mathrm{C} 6-15$ to $70 \mathrm{E} 4-6$, respectively. They were obtained from the Bloomington Stock Center.

\section{Northern analysis and whole-mount RNA hybridization}

RNA was extracted and run over an oligo(dT) column according to Lev and Segev (1986). Poly(A) ${ }^{+}$RNA $(25 \mu \mathrm{g})$ was separated on an agarose-formaldehyde gel, blotted to Hybond-N (Amersham), and hybridized with $50 \%$ formamide at $58^{\circ} \mathrm{C}$. An antisense RNA probe was prepared from the 2.3-kb DFGF-R cDNA. Whole-mount RNA hybridization was performed as described in Tautz and Pfeifle (1989), except for the following changes: Dioxigenin-labeled RNA probes were prepared using the Boehringer Mannheim RNA kit, according to the manufacturer's recommendations. The dioxigenin-labeled RNA was size reduced by alkaline hydrolysis. Hybridizations and washes were carried out at $55^{\circ} \mathrm{C}$, and the probe was visualized with HRPconjugated anti-dioxigenin antibody (Boehringer Mannheim). The antibody was preabsorbed overnight at $4^{\circ} \mathrm{C}$ against fixed embryos and applied for $2 \mathrm{hr}$ at room temperature at a $1: 400$ dilution in PBS, $0.1 \%$ Tween 20 , and $5 \%$ normal goat serum, after embryos had been blocked for $1 \mathrm{hr}$ in the same solution.
Expression of fusion proteins, production of antibodies, and staining of embryos

For expression of DFGF-R fusion proteins, the 768-bp BamHIBglII fragment from the cDNA clone encoding the extracellular domain was cloned into the BamHI site of the pATHl vector (Dieckmann and Tzagaloff 1985). The BamHI site comes from the Bluescript vector. Similarly, the BgIII-HindIII 1.4-kb fragment of the cDNA clone encoding the transmembrane and the entire cytoplasmic domain (the HindIII site comes from the vector) was cloned into pATH1 digested with BamHI and HindIII. The fusion proteins were induced, purified, and eluted as described previously (Zak et al. 1990). The fusion protein, 60 $\mu \mathrm{g}$, was injected into guinea pigs, and two boosts were given at 10- to 14-day intervals. After bleeding, the antiserum was cleaned by passage over Affigel 10 plus Affigel 15 column (Bio$\mathrm{Rad}$ ) in a ratio of $3: 1$, linked to bacterial proteins and the original, nonfused trpE protein.

Staining of embryos was carried out as described previously (Zak et al. 1990). For secondary antibodies, goat-anti-guinea pig antibodies that were conjugated either to HRP or rhodamine were used (Jackson Laboratories). For the detection of the crumbs protein, embryos derived from the cross between flies bearing the overlapping $70 \mathrm{C}$ deficiencies were incubated with monoclonal crumbs antibodies, followed by incubation with HRP-conjugated goat-anti-mouse antibodies.

\section{Acknowledgments}

We thank Y. Yarden and D. Givol for generously providing the mouse FGF-R cDNA probe, E. Knust for the crumbs antibody, and all members of the Shilo lab for ideas, discussion, and criticism. This work was supported by grants (B.S.) from the Israeli Academy of Sciences and National Institutes of Health (GM35998).

The publication costs of this article were defrayed in part by payment of page charges. This article must therefore be hereby marked "advertisement" in accordance with 18 USC section 1734 solely to indicate this fact.

\section{References}

Burgess, W.H. and T. Macing. 1989. The heparin-binding (fibroblast) growth factor family of proteins. Annu. Rev. Biochem. 958: 575-606.

Campos-Ortega, J.A. and V. Hartenstein. 1985. The embryonic development of Drosophila melanogaster. Springer-Verlag, Berlin.

Dieckmann, C.L. and A. Tzagaloff. 1985. Assembly of the mitochondrial membrane system. $\mathrm{CBP} 6$, a yeast nuclear gene necessary for synthesis of cytochrome b. I. Biol. Chem. 260: $1513-1520$.

Dionne, C.A., G. Crumley, F. Bellot, J.M. Kaplow, G. Searfoss, M. Ruta, W.H. Burgess, M. Jaye, and J. Schlessinger. 1990 Cloning and expression of two distinct high-affinity receptors cross-reacting with acidic and basic fibroblast growth factors. $E M B O I$. 9: 2685-2692.

Doctor, J.S., F.M. Hoffmann, and B.B. Olwin. 1990. Identification of a fibroblast growth factor receptor in Drosophila melanogaster. Mol. Cell. Biol. (in press).

Folkman, J. and M. Klagsbrun. 1987. Angiogenic factors. Science 235: 442-447.

Gertler, F.B., R.L. Bennett, M.J. Clark, and F.M. Hoffmann. 1989. Drosophila abl tyrosine kinase in embryonic CNS axons: A role in axogenesis is revealed through dosage-sensi- 
tive interactions with disabled. Cell 58: 103-113.

Gospodarowicz, D.E. 1974. Localisation of a fibroblast growth factor and its effect alone and with hydrocortisone on 3T3 cell growth. Nature 249: 123-127.

Grenningloh, G., A.J. Bieber, E.J. Rehm, P.M. Snow, Z.R. Traquina, M. Hortsch, N.H. Patel, and C.S. Goodman. 1991. Molecular genetics of neuronal recognition in Drosophila: Evolution and function of immunoglobulin superfamily cell adhesion molecules. Cold Spring Harbor Symp. Quant. Biol. 55: (in press).

Hafen, E., K. Basler, J.E. Edstrom, and G.M. Rubin. 1987. sevenless, a cell-specific homeotic gene of Drosophila, encodes a putative transmembrane receptor with a tyrosine kinase domain. Science 236: 55-63.

Hattori, Y., H. Odagiri, H. Nakatani, K. Miyagawa, K. Naito, H. Sakamoto, O. Katoh, T. Yoshida, T. Sugimura, and M. Terada. 1990. K-sam, an amplified gene in stomach cancer, is a member of the heparin-binding growth factor receptor genes. Proc. Natl. Acad. Sci. 87: 5983-5987.

Hoffmann, F.M. 1990. Roles of Drosophila proto-oncogene and growth factor homologs during development of the fly. Curr. Top. Microbiol. Immunol. 147: 1-29.

Jaye, M., R.M. Lyall, R. Mud, J. Schlessinger, and N. Sarver. 1988. Expression of acidic fibroblast growth factor cDNA confers growth advantage and tumorigenesis to Swiss 3T3 cells. EMBO I. 7: 963-969.

Jürgens, G., E. Wieschaus, C. Nüsslein-Volhard, and H. Kluding. 1984. Mutations affecting the pattern of the larval cuticle in Drosophila melanogaster. Zygotic loci on the third chromosome. Wilhelm Roux's Arch. Dev. Biol. 193: 283-295.

Kimmelman, D. and M. Kirschner. 1987. Synergistic induction of mesoderm by FGF and TGF-beta and the identification of an mRNA coding for FGF in the early Xenopus embryo. Cell 51: 869-877.

Kimmelman, D., J.A. Abraham, T. Haaparanta, T.M. Palisi, and M.W. Kirschner. 1988. The presence of fibroblast growth factor in the frog egg: Its role as a natural mesoderm inducer. Science 242: 1053-1056.

Kornbluth, S., K.E. Paulson, and H. Hanafusa. 1988. Novel tyrosine kinase identified by phosphotyrosine antibody screening of cDNA libraries. Mol. Cell. Biol. 8: 5541-5544.

Lee, P.L., D.E. Johnson, L.S. Cousens, V.A. Fried, and L.T. Williams. 1989. Purification and complementary cDNA cloning of a receptor for basic fibroblast growth factor. Science 245: 57-60.

Lev, Z. and O. Segev. 1986. The RNA transcripts of Drosophila melanogaster src gene are differentially regulated during development. Biochim. Biophys. Acta 867: 144-151.

Lev, Z., B-Z. Shilo, and Z. Kimchie. 1985. Developmental changes in expression of the Drosophila melanogaster epidermal growth factor receptor gene. Dev. Biol. 110: 499-502.

Musci, T.J., E. Amaya, and M.W. Kirschner. 1990. Regulation of the fibroblast growth factor receptor in early Xenopus embryos. Proc. Natl. Acad. Sci. 87: 8365-8369.

Neufeld, G. and D. Gospodarowicz. 1986. Basic and acidic fibroblast growth factors interact with the same cell surface receptor. J. Biol. Chem. 261: 5631-5637.

Neufeld, G., R. Mitchell, P. Ponte, and D. Gospodarowicz. 1988. Expression of human basic fibroblast growth factor CDNA in baby hamster kidney-derived cells results in autonomous cell growth. J. Cell Biol. 106: 1385-1394.

Pasquale, E.B. 1990. A distinctive family of embryonic proteintyrosine kinase receptors. Proc. Natl. Acad. Sci. 87: 58125816.

Pawson, T. and A. Bernstein. 1990. Receptor tyrosine kinases: Genetic evidence for their role in Drosophila and mouse development. Trends Genet. 6: 350-356.

Petruzzelli, L., R. Herrara, R. Arenas-Garcia, R. Fernandez, M. Birnbaum, and O. Rosen. 1986. Isolation of a Drosophila sequence homologous to the kinase domain of the human insulin receptor and detection of the phosphorylated Drosophila receptor with an anti-peptide antibody. Proc. Natl. Acad. Sci. 83: 4710-4714.

Poole, S.J., L.M. Kauvar, B. Drees, and T. Kornberg. 1985. The engrailed locus of Drosophila: Structural analysis of an embryonic transcript. Cell 40: 37-43.

Price, J.V., R.J. Clifford, and T. Schupbach. 1989. The maternal ventralizing locus torpedo is allelic to faint little ball, an embryonic lethal, and encodes the Drosophila EGF receptor homolog. Cell 56: 1085-1092.

Reid, H.H., A.F. Wilks, and O. Bernard. 1990. Two forms of basic fibroblast growth factor receptor-like mRNA are expressed in the developing mouse brain. Proc. Natl. Acad. Sci. 87: 1596-1600.

Rogelj, S., R.A. Weinberg, P. Fanning, and M. Klagsbrun. 1988. Basic fibroblast growth factor fused to a signal peptide transforms cells. Nature 331: 173-175.

Ruta, M., R. Howk, G. Ricca, W. Drohan, M. Zabelshansky, G. Laureys, D.E. Barton, U. Francke, J. Schlessinger, and D. Givol. 1988. A novel protein-tyrosine kinase gene whose expression is modulated during endothelial cell differentiation. Oncogene 3: 9-15.

Safran, A., A. Avivi, A. Orr-Urtereger, G. Neufeld, P. Lonai, D. Givol, and Y. Yarden. 1990. The murine $f l g$ gene encodes a receptor for fibroblast growth factor. Oncogene 5: 635-643.

Schejter, E.D. and B-Z. Shilo. 1989. The Drosophila EGF receptor homolog (DER) gene is allelic to faint little ball, a locus essential for embryonic development. Cell 56: 1093-1104.

Seeger, M.A., L. Haffley, and T.C. Kaufman. 1988. Characterization of amalgam: A member of the immunoglobulin superfamily from Drosophila. Cell 55: 589-600.

Shilo, B.-Z. 1987. Proto-oncogenes in Drosophila melanogaster. Trends Genet. 3: 69-72.

Slack, J.M.W., B.G. Darlington, J.K. Heath, and S.F. Godsave. 1987. Mesoderm induction in early Xenopus embryos by heparin-binding growth factors. Nature 326: 197-200.

Snow, P.M., A.J. Beiber, and C.S. Goodman. 1989. Drosophila fasciclin III: A novel homophilic adhesion molecule. Cell 59: 313-323.

Sprenger, F., L.M. Stevens, and C. Nusslein-Volhard. 1989. The Drosophila gene torso encodes a putative receptor tyrosine kinase. Nature 338: 478-483.

Streuli, M., N.X. Krueger, A.Y.M. Tsai, and H. Saito. 1989. A family of receptor-linked protein tyrosine phosphatases in human and Drosophila. Proc. Natl. Acad. Sci. 86: 86988702.

Tautz, D. and C. Pfeifle. 1989. A non-radioactive in situ hybridization method for the localization of specific RNAs in Drosophila embryos reveals translational control of the segmentation gene hunchback. Chromosoma 98: 81-85.

Tepass, U., C. Theres, and E. Knust. 1990. crumbs encodes an EGF-like protein expressed on apical membranes of Drosophila epithelial cells and required for organization of epithelia. Cell 61: 787-799.

Williams, A.F. and A.N. Barclay. 1988. The immunoglobulin superfamily-Domains for cell surface recognition. Annu. Rev. Immunol. 6: 381-405.

Zak, N.B., R.J. Wides, E.D. Schejter, E. Raz, and B.-Z. Shilo. 1990. Localization of the DER/flb-protein in embryos: Implications on the faint little ball lethal phenotype. Development 109: 865-874. 


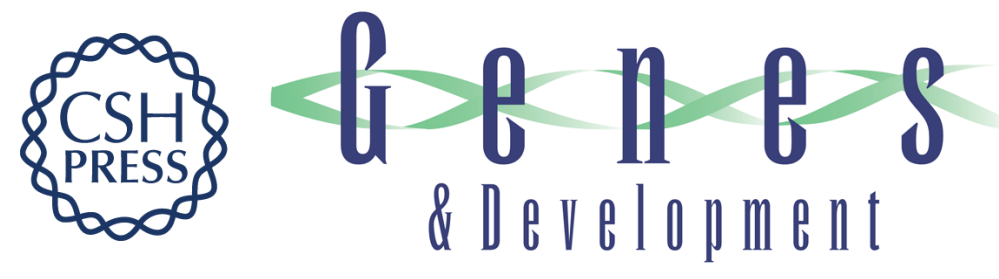

\title{
The Drosophila FGF-R homolog is expressed in the embryonic tracheal system and appears to be required for directed tracheal cell extension.
}

\author{
L Glazer and B Z Shilo
}

Genes Dev. 1991, 5:

Access the most recent version at doi:10.1101/gad.5.4.697

References This article cites 40 articles, 15 of which can be accessed free at:

http://genesdev.cshlp.org/content/5/4/697.full.html\#ref-list-1

\section{License}

Email Alerting Receive free email alerts when new articles cite this article - sign up in the box at the top Service right corner of the article or click here.

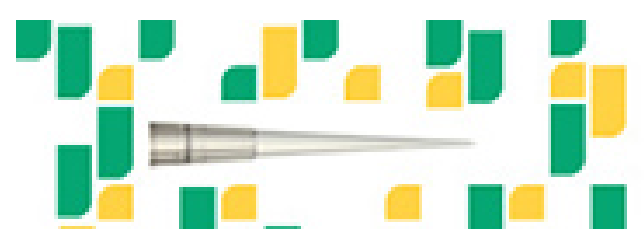

Focused on your science. 